\title{
Xenogeneic materials for the surgical treatment of aortic infections
}

\author{
Paula R. Keschenau ${ }^{1 \wedge}$, Alexander Gombert ${ }^{1}$, Mohammed E. Barbati ${ }^{1}$, Houman Jalaie ${ }^{1}$, \\ Johannes Kalder $^{1} \wedge$, Michael J. Jacobs ${ }^{1,2}$, Drosos Kotelis ${ }^{1}$
}

${ }^{1}$ European Vascular Center Aachen-Maastricht, Department of Vascular Surgery, RWTH University Hospital Aachen, Aachen, Germany; ${ }^{2}$ European Vascular Center Aachen-Maastricht, Department of Vascular Surgery, AZM University Hospital Maastricht, Maastricht, The Netherlands Contributions: (I) Conception and design: PR Keschenau, D Kotelis; (II) Administrative support: A Gombert, MJ Jacobs, H Jalaie, J Kalder; (III) Provision of study materials or patients: MJ Jacobs, H Jalaie, J Kalder, D Kotelis; (IV) Collection and assembly of data: PK Keschenau; (V) Data analysis and interpretation: PR Keschenau, A Gombert, ME Barbati; (VI) Manuscript writing: All authors; (VII) Final approval of manuscript: All authors.

Correspondence to: Michael J. Jacobs, MD, PhD. European Vascular Center Aachen-Maastricht, Department of Vascular Surgery, RWTH University Hospital Aachen, Pauwelsstr. 30, 52074 Aachen, Germany. Email: mjacobs@ukaachen.de.

Background: The surgical treatment of aortic infections (AIs) is challenging. In situ aortic reconstructions represent nowadays the favored therapy for fit patients and xenogeneic materials are used increasingly. The aim of this study was to present our experience with xenogeneic reconstructions for AI using self-made bovine pericardium tubes and/or the biosynthetic Omniflow ${ }^{\circledR}$ II graft.

Methods: This retrospective single-center study included all patients undergoing xenogeneic aortic and aortoiliac reconstructions from December 2015 to June 2020. Patient comorbidities, symptoms, procedural characteristics, types of pathogens and postoperative outcomes were analyzed.

Results: Twenty-eight patients $[23$ male (82\%), median age 68 (range, 28-84) years] were included. Ten patients (36\%) had native AIs and 18 (64\%) had graft infections, including 3 (11\%) aortoesophageal and $2(7 \%)$ aortoduodenal fistulas (ADF). Twenty-four patients $(86 \%)$ were symptomatic, the most common symptoms being contained aortic rupture $(n=8)$ and sepsis $(n=4)$. The surgical procedures were infra- and juxtarenal aortic repairs $(n=11,39 \%$ and $n=7,25 \%)$, thoracoabdominal aortic repairs (type IV: $n=1,4 \%$; type $V: n=3,11 \%)$, descending thoracic aortic repairs $(n=4,14 \%)$ and 2 reconstructions $(7 \%)$ involving the ascending aorta/aortic arch. Most were urgent $(n=10,43 \%)$ or emergent operations $(n=11,35 \%)$. Identification of pathogen(s), mostly Gram-positive bacteria, was possible in 25 patients (89\%). Twelve patients $(43 \%)$ had polymicrobial infections and $6(21 \%)$ infections with multi-resistant bacteria. In-hospital mortality was $32 \%(n=9)$ due to acute cardiac failure (1/9), endocarditis (1/9), bleeding (3/9) and sepsis (4/9). The most frequent complications were transient need for dialysis $(n=12,43 \%)$ and persisting sepsis ( $\mathrm{n}=11,39 \%)$. Two early occlusions of Omniflow ${ }^{\circledR}$ II grafts were observed (7\%). Median follow-up (FU), during which 2 patients died of non-aortic causes, was 14 months (95\% CI: 9-19 months). Freedom from reoperation was $100 \%$, there was no evidence for reinfection during FU.

Conclusions: Xenogeneic orthotopic reconstructions for AI can be performed at all aortic levels. Combining bovine pericardium and the Omniflow ${ }^{\circledR}$ II graft can be useful for reconstructing the branched aortic segments and both materials show appropriate early to midterm outcomes. Nonetheless, AIs are serious conditions associated with relevant morbidity/mortality rates, even in a specialized center.

Keywords: Aneurysm; infected; prosthesis-related infections; bioprosthesis; vascular grafting; transplants

Submitted Dec 10, 2020. Accepted for publication Mar 14, 2021.

doi: $10.21037 /$ jtd-20-3481

View this article at: http://dx.doi.org/10.21037/jtd-20-3481

^ ORCID: Paula R. Keschenau, 0000-0002-2823-8091; Johannes Kalder, 0000-0002-0606-2814.

(c) Journal of Thoracic Disease. All rights reserved.

F Thorac Dis 2021;13(5):3021-3032 I http://dx.doi.org/10.21037/jtd-20-3481 


\section{Introduction}

Aortic infections (AIs), including aortic graft infections (AGI) as well as mycotic aortic aneurysms (MAA), are rare $(1,2)$. However, as laid out in the recent European Society of Vascular Surgery (ESVS) guidelines on AGI management, they represent a special challenge in clinical practice $(1,2)$. One reason is the wide range of possible symptoms from clinically almost unapparent conditions to emergency situations in case of sepsis and/or rupture with consequently very high mortality rates of up to $43-75 \%$ (1-3).

Surgical therapy is usually required and orthotopic reconstruction, with graft explantation in case of AGI, is considered the treatment of choice (1). However, the choice of graft material is still a matter of debate $(4,5)$. Xenogeneic materials are increasingly used because of the unlimited availability, good biocompatibility, avoidance of harvesting trauma and low reinfection rates (6). Most publications on xenogeneic reconstructions for AIs report the use of bovine pericardium (5,7-9). Another option is the biosynthetic Omniflow ${ }^{\circledR}$ II graft, for which favorable results have been shown when used for peripheral arterial reconstructions in an infected field $(10,11)$. However, only few studies describe its use in the aortoiliac segment (12-15).

The aim of this study was to present our experience with xenogeneic aortic and aortoiliac reconstructions using bovine pericardium and the biosynthetic Omniflow ${ }^{\circledR} \mathrm{II}$ graft either individually or as a composite graft.

We present the following article in accordance with the STROBE reporting checklist (available at http://dx.doi. org/10.21037/jtd-20-3481).

\section{Methods}

This was a retrospective single-center study. All patients who, in our center, underwent open aortic or aortoiliac reconstructions using xenogeneic grafts between December 2015 and June 2020 were included. These were all patients treated for aortic or aortoiliac infections during this time period. Indications, patient and procedural characteristics as well as the postoperative course including complications, mortality and follow-up were analyzed retrospectively. The study was conducted in accordance with the Declaration of Helsinki (as revised in 2013). Ethical board approval was obtained (EK 20-031), individual consent waived due to the retrospective study design. Results are reported according to the recommendations for reporting treatment of AGI (16).

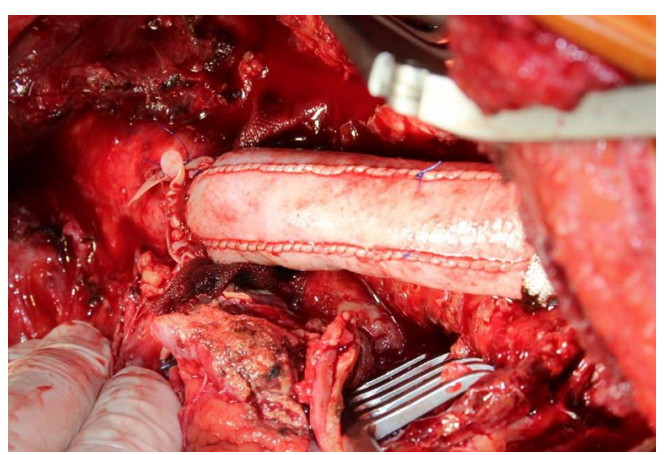

Figure 1 Self-made bovine pericardium tube graft for aortic reconstruction. It is manufactured on-table from a rectangular pericardium patch by suturing it around a metal dilator or a syringe of the respective size. We use a double running suture line with intermittent knots so that the length of the graft can be adjusted as required.

\section{Xenogeneic graft materials}

Either a bovine pericardium patch (XenoSure ${ }^{\circledR}$ Biologic Patch, LeMaitre Vascular, Sulzbach/Ts., Germany) or the ovine Omniflow ${ }^{\circledR}$ II Biosynthetic Vascular Prosthesis (LeMaitre Vascular, Sulzbach/Ts., Germany) or a combination of both materials were used to perform an orthotopic reconstruction. The choice of graft material was made individually by the surgeon and the xenogeneic graft was self-made during the procedure. Bovine pericardium was used to manufacture a tube graft (Figure 1) and an 8-mm Omniflow ${ }^{\circledR}$ II vascular prosthesis was used for reconstruction of the aortic bifurcation or of visceral arteries (Figure $2 A, B, C$ ).

\section{Indications for orthotopic xenogeneic reconstruction}

In one of the patients the indication for xenogeneic reconstruction was given due to a high risk for graft infection after extirpation of a very extensive malignoma with infiltration of the aortoiliac vessels and indication for subsequent chemotherapy and radiation. In all other patients xenogeneic reconstruction was performed for microbiologically proven or clinically suspected graft or native vessel infection. The diagnostic strategy was according to the criteria proposed by the MAGIC (Management of Aortic Graft Infection) group (17). In brief, after taking the medical history and a blood sample for laboratory analysis as well as blood cultures, all 

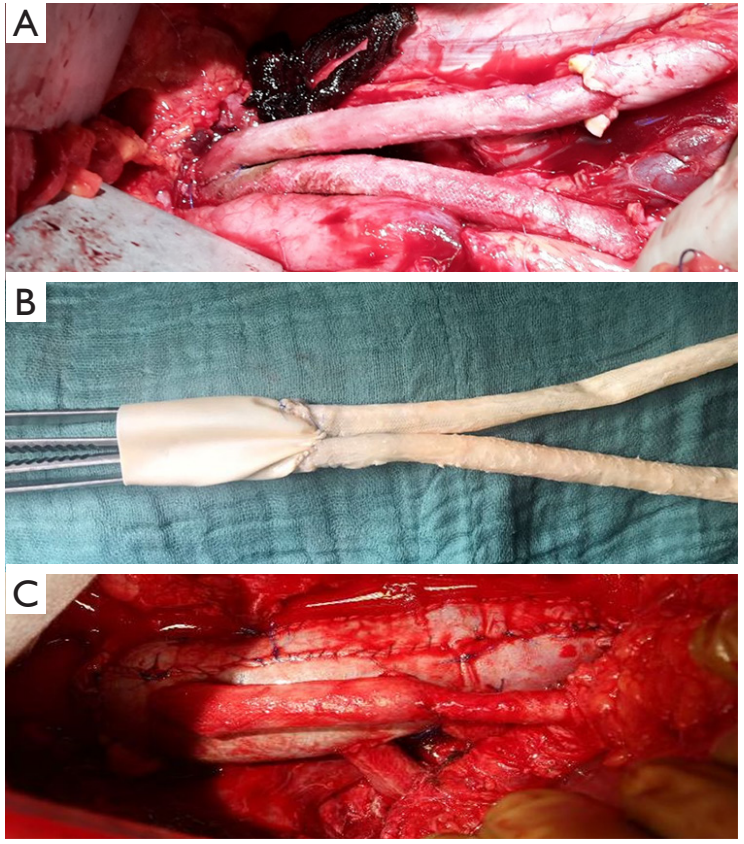

Figure 2 Omniflow ${ }^{\circledR}$ II graft used for xenogeneic reconstruction. (A) Reconstruction of the aortic bifurcation using only the Omniflow ${ }^{\circledR}$ II graft; (B) composite reconstruction of the aortic bifurcation consisting of a bovine pericardium tube and the Omniflow ${ }^{\circledR}$ II graft; (C) composite reconstruction of the visceral aorta using a bovine pericardium tube graft and the Omniflow ${ }^{\circledR}$ II graft for the visceral artery bypasses.

patients underwent a clinical examination and a computed tomography angiography (CTA) scan of the entire aorta. Further diagnostic steps were depending on the urgency of the situation, clinical presentation and the type of the (suspected) problem. For instance, when a periaortic fluid collection was detected that could be reached by CT-guided puncture, this was used for gathering a sample for microbiological analysis. When a fistula was suspected, endoscopy was performed (bronchoscopy and/ or gastroduodenoscopy and /or colonoscopy, depending on the localization). An additional 18-fluoro-D-deoxyglucose positron emission tomography/computed tomography (18-FDG-PET CT) scan is usually performed, especially in patients with low grade infections and thus little symptoms and often unremarkable findings on the CTA scan

\section{Surgical protocol}

The surgical access was a thoracolaparotomy through the $5^{\text {th }}$ to $8^{\text {th }}$ intercostal space for thoracic and thoracoabdominal aortic procedures, a sternotomy for treatment of an infected aneurysm of the brachiocephalic trunc and a clamshell access in a patient who needed simultaneous replacement of the ascending aorta, aortic arch and proximal descending aorta. Aortic and aortoiliac procedures were performed using a transperitoneal approach through a median laparotomy.

Thoracic and thoracoabdominal aortic procedures were realized according to our standard protocol for organ protection (18) including the use of cerebrospinal fluid drainage (CSFD), intraoperative monitoring of motor evoked potentials (MEPs), sequential aortic clamping if possible, extracorporeal circulation (ECC) with distal aortic perfusion as well as selective visceral perfusion under mild hypothermia of 32 to $33{ }^{\circ} \mathrm{C}$ and, since 2015 , cold renal perfusion using $4{ }^{\circ} \mathrm{C}$ Custodiol ${ }^{\circledast}$. If the ascending aorta and the aortic arch where involved, the operation was performed in moderate hypothermic circulatory arrest $\left(25^{\circ} \mathrm{C}\right)$ and with antegrade cerebral perfusion as well as with additional transcranial doppler and electroencephalography monitoring. Following thoracic and thoracoabdominal aortic surgery, the mean arterial pressure (MAP) was adjusted based on MEPs and the intracranial pressure (ICP) was kept $\leq 10 \mathrm{mmHg}$ during the first 48 to 72 hours postoperatively.

In all patients with graft infections the infected graft was removed completely.

Whenever possible intraoperative samples of the graft or aortic/aortoiliac tissue were gathered for microbiological analysis, otherwise swabs were taken from the aorta and periaortic area. Furthermore, a local debridement was performed by resecting periaortic/perigraft tissue and followed by rinsing with a polyhexanide solution and saline.

\section{Adjunctive measures}

All patients received an individualized perioperative antiinfective treatment after consulting with an infectiology specialist. If the pathogen was not known this was a calculated broad-spectrum therapy which was adapted as soon as the microbiological test results including resistance testing were available. The intraoperative antibiotic prophylaxis was chosen similarly. In non-emergent cases it was our goal to achieve an optimal infection control preoperatively. The duration of preoperative antibiotic therapy in those cases was usually at least two weeks intravenously. When the blood cultures were positive, the surgery was deferred until negative blood cultures could be 
asserted. The duration of a prolonged anti-infective treatment after discharge was determined individually according to the recommendation of the infectiology specialist.

Moreover, adjunctive interdisciplinary surgical measures were required in a number of patients. For instance, all patients with aortoesophageal fistula (AEF) underwent a staged treatment as described before (19), including esophagectomy followed by aortic reconstruction and, in a third stage, esophageal reconstruction. In patients with aortoduodenal fistula (ADF) an intestinal Rouxen-Y reconstruction was performed. The patient with the ureteral fistula underwent ureteral splinting prior to surgery followed by intraoperative end-to-end reconstruction of the ureter and placement of a temporary nephrostomy. Finally, in one patient presenting with a ruptured type $\mathrm{V}$ thoracoabdominal aortic aneurysm following MRSAassociated TEVAR infection and pleural empyema a simultaneous atypical resection of the destructed lower pulmonary lobe was necessary.

\section{Anticoagulation regime}

Intraoperatively all patients were anticoagulated with heparin aiming at an activated clotting time $>200$ seconds or $>400$ seconds if extracorporeal circulation was used. Postoperatively, prophylactic heparin and a single antiplatelet therapy (aspirin, $100 \mathrm{mg}$ daily, or clopidogrel, $75 \mathrm{mg}$ daily, in case of an allergy) were administered. Stronger anticoagulation was not given routinely, only when specific indications (e.g., atrial fibrillation) existed.

\section{Follow-up (FU)}

Whenever possible, the follow-up information was obtained from clinical routine controls including physical examination and imaging by duplex ultrasound and/ or computed-tomography (CT)-angiography. In case of unavailability of those data, the patients were contacted for a telephone interview.

\section{Statistical analysis}

The statistical analysis was performed using SPSS Statistics for Windows, version 25 (IBM, Armonk, USA). Aside from the Kaplan-Meier survival analysis and calculation of median FU using the reverse Kaplan-Meier method according to Schemper et al. (20), only descriptive statistics are reported because of the small cohort size. The data are described as percentages, rounded to whole numbers in order to enhance readability, or as median and range. A $10 \%$ standard error was defined as a cut-off point for the Kaplan-Meier analysis. The patients lost to FU were excluded from the Kaplan-Meier analysis.

\section{Results}

\section{Patient characteristics}

A total of 28 patients were included. Twenty-three patients $(82 \%)$ were male. The median age was 68 years (range, 28-84 years). Patient demographics and comorbidities are reported in Table 1. According to the MAGIC recommendation (17), the leading diagnostic criteria for AI were laboratory findings (positive cultures, elevated inflammatory markers) in 25 patients (89\%) and clinical plus radiological findings, including suspicious fluorodeoxyglucose (FDG)-positron emission tomography (PET) scan, in the other 3 patients (11\%). Ten patients (29\%) had native AIs and 18 patients (64\%) had graft infections, including 3 (11\%) AEF and 2 (7\%) ADF. A detailed overview over the types of infected aortic grafts, respectively the types of prior aortic procedures, is given in Table 2. All graft infections were cavitary infections (15). Furthermore, 16 were late ( $>4$ months) and 2 early graft infections. Additionally, 4 patients (14\%) had a history of abdominal non-aortic surgery. Twenty-four patients (86\%) were symptomatic with varying clinical presentation. The most common symptoms were contained aortic rupture in 8 patients (29\%) followed by sepsis in 4 patients (14\%) whereas mild or unspecific symptoms were less frequent. Table 3 gives an overview over symptoms and laboratory parameters.

\section{Procedural characteristics}

As demonstrated in Table 4 most of the procedures were urgent $(n=10,36 \%)$ or emergent operations $(n=11,39 \%)$. The majority were infrarenal and juxtarenal aortic repairs ( $\mathrm{n}=11,39 \%$ and $\mathrm{n}=7,25 \%$, respectively). One patient (4\%) underwent a thoracoabdominal type IV repair, 3 patients (11\%) underwent type $\mathrm{V}$ thoracoabdominal aortic repairs and 4 patients (14\%) underwent thoracic aortic repairs. Moreover, 1 patient (4\%) with an AEF and a history of ascending and aortic arch repair as well as TEVAR as a bridging procedure was treated by a redo replacement of the ascending aorta, aortic arch and proximal descending aorta via a clamshell approach and 1 patient (4\%) with an 
Table 1 Patient characteristics

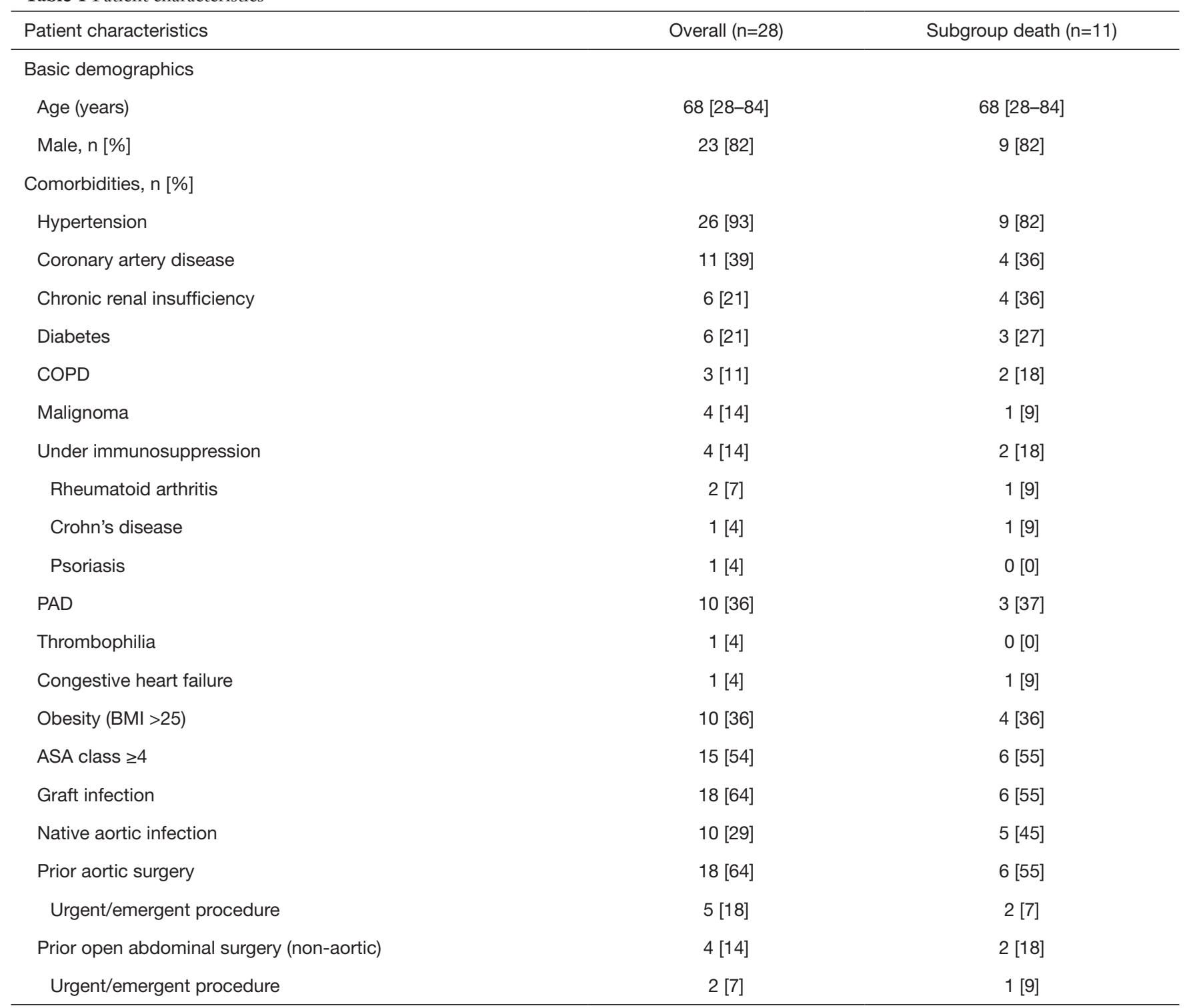

Data are presented as $\mathrm{n}$ [\%] or median [range]. PAD, peripheral arterial disease; COPD, chronic obstructive pulmonary disease; BMI, body mass index; ASA, America Society of Anesthesiologists.

infected aneurysm of the brachiocephalic trunc was treated by aneurysm resection and bypasses from the ascending aorta to the right carotid and right subclavian arteries.

The median operating time was 383 minutes (247585 minutes).

\section{Pathogens}

The responsible microorganism(s) were identified in 25 patients $(89 \%)$ based on positive blood cultures alone $(2 / 25)$, positive cultures from intraoperative specimens or periaortic aspirate $(15 / 25)$ or a combination of both of the aforementioned sources (7/25). Gram-positive bacteria were found in 32 cases, Gram-negative bacteria in 7 cases and fungi in 5 cases. The types of identified pathogens are presented in Figure 3.12 patients (43\%) had infections with multiple microorganisms and 6 patients $(21 \%)$ with multiresistant bacteria. 
Table 2 Types of aortic graft infections/prior aortic procedures

\begin{tabular}{lc}
\hline $\begin{array}{l}\text { Type of graft infection/prior aortic } \\
\text { procedure }\end{array}$ & $\begin{array}{c}\text { Total patient number: } \\
\mathrm{n}=28\end{array}$ \\
\hline AEF & $3[11]$ \\
After TEVAR & $2[7]$ \\
After ascending + arch OAR & $1[4]$ \\
ADF & $2[7]$ \\
After infrarenal OAR & $2[7]$ \\
Infrarenal OAR & $4[14]$ \\
BEVAR & $1[4]$ \\
TEVAR + chimney & $2[7]$ \\
TEVAR + chimney left subclavian artery & $1[4]$ \\
TEVAR + reverse chimney celiac trunc & $1[4]$ \\
EVAR & $6[21]$ \\
\hline
\end{tabular}

Data are presented as $\mathrm{n}$ [\%]. Percentages are calculated referring to the total study population of 28 patients. AEF, aortoesophageal fistula; ADF, aortoduodenal fistula; OAR, open aortic repair; EVAR, endovascular aortic repair; TEVAR, thoracic EVAR; BEVAR, branched EVAR.

\section{Early outcomes}

In-hospital mortality was $32 \%(n=9)$. One patient died intraoperatively during an urgent TAA repair due to acute cardiac insufficiency. He suffered from congestive heart failure (ejection fraction $<40 \%$ ) and had requested the operation despite the high operative risk. One patient developed endocarditis of the aortic valve and died due to subsequent refractory ventricular fibrillation. Four patients died due to sepsis despite maximal therapy. In one of those patients, the postoperative course was complicated by acute mesenteric ischemia due to an early aortomesenteric bypass occlusion requiring, after mesenteric revascularization, hemicolectomy and small bowel resection. Finally, 3 patients had recurrent diffuse bleeding from the operating site requiring reoperations. One of those patients had undergone extirpation of an extensive retroperitoneal tumor and showed a very rapid tumor progression postoperatively so that a palliative care approach was ultimately adopted. In the two other patients, the combination of septic and hemorrhagic shock was fatal. There were no anastomotic breakdown and no signs of residual infection in the operative situs in those patients.

The median duration of stay in the intensive care unit was 6 days (3-147 days) and the median duration of hospital stay was 30 days (4-177 days). The early morbidity is summarized in Table 5. The most common complication was acute renal insufficiency requiring transient dialysis in 12 patients (43\%). Seven of those patients died while on dialysis but none of the survivors required permanent dialysis. The second most frequent complication was persisting sepsis $(\mathrm{n}=11,39 \%)$, mainly due to pulmonary infections $(\mathrm{n}=8,29 \%)$. Notably, the postoperative course was complicated by early occlusions of Omniflow ${ }^{\circledR}$ II bypasses in 2 patients (7\%). One of those was the abovementioned case of mesenteric ischemia and in the other patient this was the result of an impaired run-off due to peripheral arterial disease. Six patients $(21 \%)$ had an uncomplicated postoperative course.

\section{Late outcomes and reinterventions}

Median estimated FU was 14 months (95\% confidence interval: 9-19 months). Two patients were lost to FU and 2 of the remaining 17 patients died during $\mathrm{FU}$ due to non-aortic causes, one patient 15 months after discharge and the other 33 months after discharge. Figure 4 shows the Kaplan-Meier estimate of over-all survival. The estimated overall survival was $61 \%$.

None of the patients required aortic reoperations during FU. and there was no evidence for reinfection, based on clinical and laboratory examinations, routine ultrasound and CTA controls, neither among the surviving nor among the deceased patients. The only non-aortic surgical intervention was an incisional hernia repair in a patient following juxtarenal aortic repair.

The patient who had undergone xenogeneic infrarenal aortic reconstruction with reconstruction of the ureter and temporary percutaneous nephrostomy for an iatrogenic ureteral fistula complained of persisting weakness, weight loss and diarrhea 4 weeks postoperatively. A campylobacter jejuni infection and a urinary infection with Enterococcus faecium were found as cause although no bacteria had been detected before and during the initial surgery. After completion of the antibiotic treatment, which was complicated by a mild candida esophagitis, his symptoms resolved. In all other patients the $\mathrm{FU}$ was uncomplicated. Thus, the hospital readmission rate was $13 \%(2 / 15)$.

Table $\mathrm{S} 1$ gives a detailed case by case overview over the included patients and procedures, microorganisms and outcomes.

\section{Discussion}

This study shows that xenogeneic orthotopic reconstructions 
Table 3 Clinical presentation

\begin{tabular}{|c|c|c|}
\hline Clinical aspect & Overall $(n=28)$ & Subgroup death $(n=11)$ \\
\hline Asymptomatic & $4[14]$ & $1[9]$ \\
\hline Symptomatic & $24[86]$ & $10[91]$ \\
\hline Unspecific/fatigue & $3[11]$ & $2[18]$ \\
\hline Pain & $1[4]$ & $0[0]$ \\
\hline Sepsis & $4[14]$ & $1[9]$ \\
\hline Recurrent GI bleeding & $1[4]$ & $1[9]$ \\
\hline Contained rupture & 8 [29] & 3 [27] \\
\hline Chronic cutaneous fistula & $1[4]$ & $0[0]$ \\
\hline \multicolumn{3}{|l|}{ Laboratory parameters } \\
\hline WBC/nL & $11[4-22]$ & 17 [6-22] \\
\hline CRP mg/L & 61 [16-350] & 81 [16-350] \\
\hline PCT mg/mL & $0.1[0-12]$ & $0.8[0-12]$ \\
\hline $\mathrm{Hb} \mathrm{g} / \mathrm{dL}$ & $10[6-15]$ & 9 [6-15] \\
\hline Hct \% & $30[18-44]$ & $27[18-41]$ \\
\hline
\end{tabular}

Data are presented as $\mathrm{n}[\%]$ or median [range]. WBC, white blood cell count; CRP, C-reactive protein; PCT, procalcitonin; Hb, hemoglobin; Hct, hematocrit.

can be performed at all aortic levels for aortic graft and native AIs leading to reasonable outcomes during early to mid-term FU. Both of the herein used graft materials, bovine pericardium and the Omniflow ${ }^{\circledR} \mathrm{II}$ graft, show good results with $100 \%$ freedom from reinfection and from aortic reintervention. The combination of both materials can be useful for reconstructing the aortic bifurcation and the viscerorenal or supra-aortic branches. Nonetheless, aortic graft and native infections (AI) are challenging conditions that are associated with relevant morbidity and mortality rates even in a specialized center.

Diagnosis and treatment of patients with AI is complex and requires multidisciplinary expertise $(1,2)$. Rifampicinsoaked grafts or silver impregnated graft have been used traditionally for in situ reconstructions for AI in the past, however it has been found that the duration of the antiinfective effect is limited. Thus, they can still represent an option for treating low grade infections, but do not represent the favored material (1). Instead, orthotopic reconstruction with non-prosthetic materials is nowadays recommended as the treatment of choice in fit patients $(1,4,21)$. Autologous vein has shown the best outcomes in terms of infection resistance and survival and, therefore, is recommended as the first choice graft material (1). However, when large caliber reconstructions are required as in abdominal AIs, only the deep femoropopliteal veins are available as autologous material. Although superior survival rates have been reported compared to antibioticsoaked or standard prosthetic graft reconstructions (22), femoropopliteal vein harvesting can cause chronic venous hypertension in up to $15 \%$ of the patients, leads to significantly longer operating times and, ideally, requires two operating teams $(4,22,23)$. This reduces the suitability of this technique in urgent or emergent settings which was the case in $78 \%$ of the herein reported procedures. Moreover, the deep femoral veins are not suitable for reconstructing the thoracic aorta. In this localization, cryopreserved homografts represent traditionally the only 
Table 4 Procedural characteristics

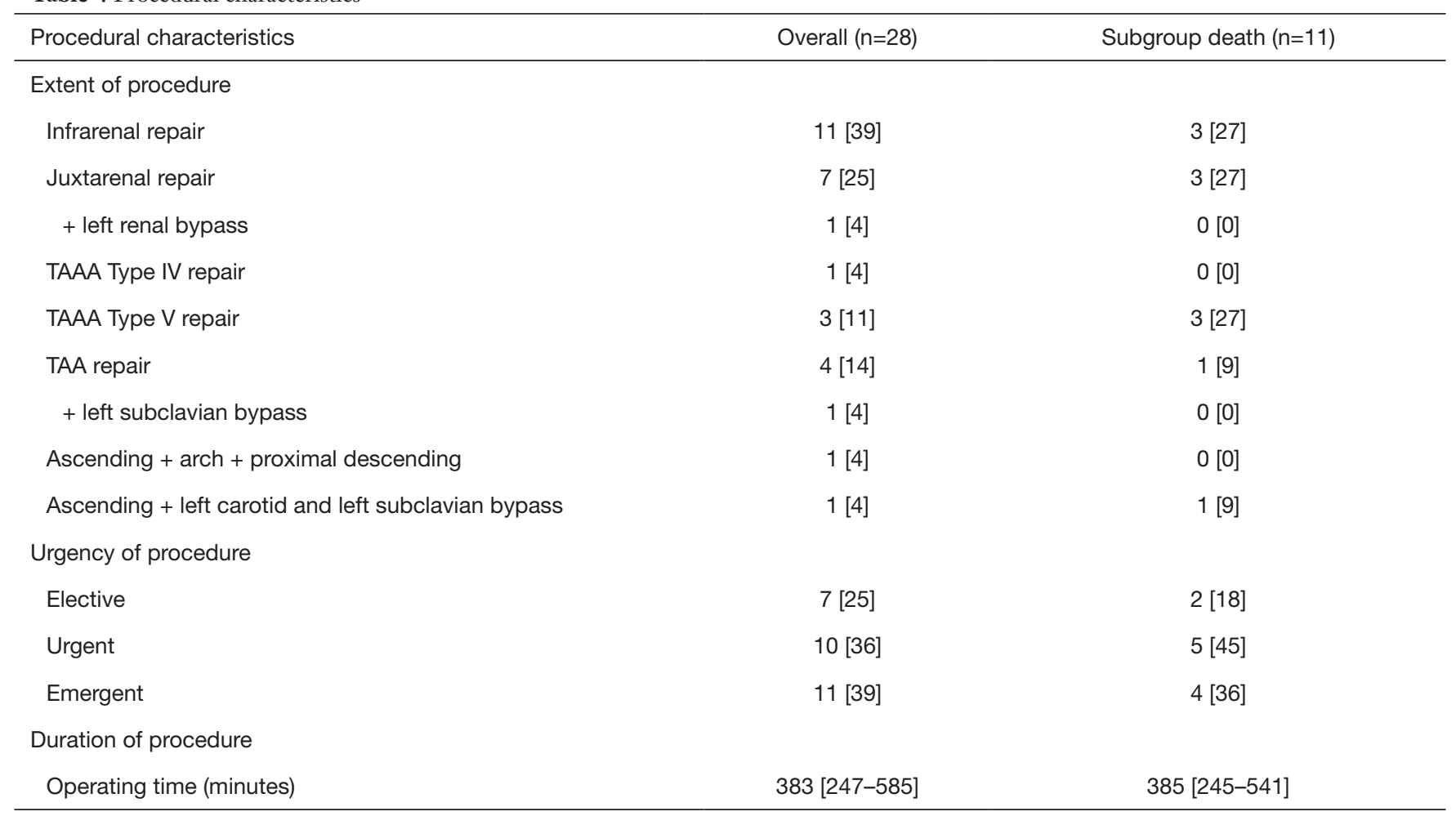

Data are presented as $n$ [\%] or median [range]. TAAA, thoracoabdominal aortic aneurysm; TAA, thoracic aortic aneurysm.

non-prosthetic alternative. However, the availability $(4,6)$, as well as the risk for re-infection, degeneration and bleeding $(4,21,24)$ as well as the still lacking long-term results (1) remain a relevant limitation of aortic reconstructions with this type of graft material. Therefore, readily available nonprosthetic materials are particularly attractive for treating AI.

Several studies have reported very good early to midterm results with self-made bovine pericardial grafts for aortic reconstructions at different levels $(5,7-9,25,26)$. In particular, the repeatedly observed high resistance to infection (freedom from reinfection up to $100 \%$ ) combined with good patency and low reintervention rates distinguish bovine pericardium from other available graft materials when used for aortic reconstructions in case of infection (7). Indeed, the high resistance of bovine pericardium to bacterial colonization has also been confirmed in vitro (27). Accordingly, no aortic reinfections or reinterventions were observed in the present study. Based on these positive properties of bovine pericardium, an off-the-shelf bifurcated pericardium graft that can be used for aortoiliac reconstructions has recently become available and two studies have reported promising results during early to midterm follow-up $(28,29)$.
In addition to reconstructing the aorta itself, 5 patients $(18 \%)$ in this study required reconstruction of the viscerorenal vessels and 2 patients (7\%) of the supra-aortic branches. Although the reconstruction of the viscerorenal aortic segment and its branches using only bovine pericardium as graft material is feasible (9), manufacturing multiple pericardium tubes intraoperatively is certainly time-consuming and, therefore, less convenient in these already highly complex procedures. The Omniflow ${ }^{\circledR}$ II graft, consisting of an ovine collagen matrix on a polyester mesh, seems to be a promising alternative for such cases. Although concerns about its resistance to bacterial colonization have been raised in an in vitro study (27), results from clinical practice, most of which regard peripheral arterial reconstructions, have shown a good infection resistance so far $(10-12,30)$. Moreover, excellent early to midterm patency without reinfection has been reported in a case series using the Omniflow ${ }^{\circledR}$ II graft for reconstruction of the aortic bifurcation alone or in combination with a bovine pericardium tube (31) and its usefulness in reconstructing the aortic arch in the event of infection has also been demonstrated (8).

The present study confirms these positive results using 


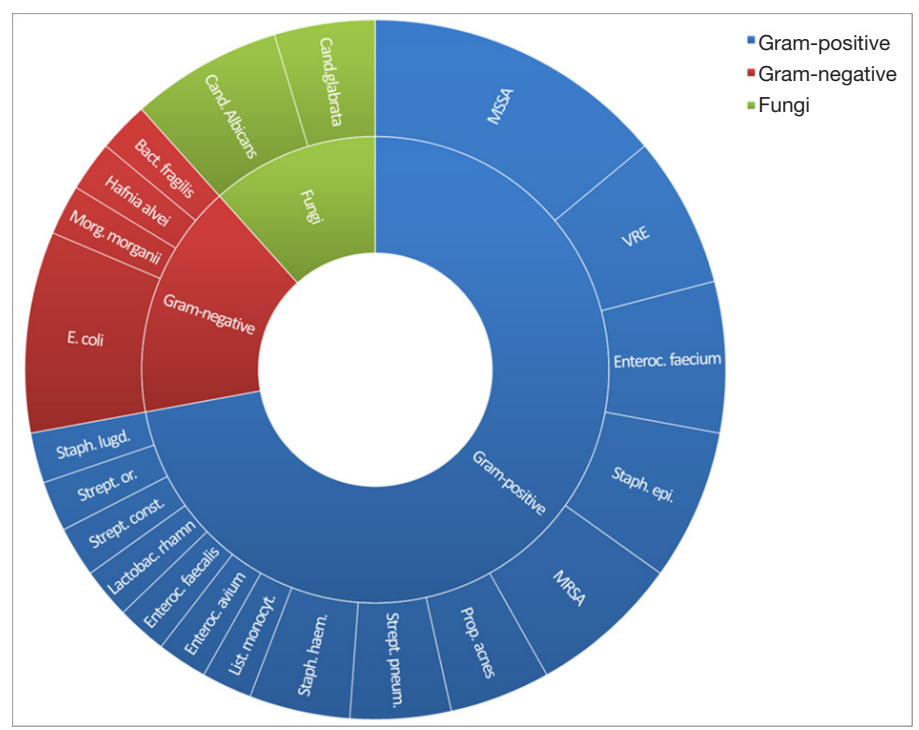

Figure 3 Overview over detected pathogens. Cand., Candida; E. coli, Eschericia coli; Bact., Bacteroides; Morg., Morganella; Staph.lugd., Stapylococcus lugdunensis; Staph. const., Stapylococcus constellatus; Staph. haem., staphylococcus haemolyticus; Staph.epi., Staphylococcus epidermidis; Strept.or., Streptococcus oralis; Strept. pneum., Streptococcus pneumonia; Lactobac.rhamn, Lactobacillus rhamnosus; Enteroc., Enterococcus; List.moncyt., Listeria monocytogenes; Prop., Propionibacterium; MSSA, methicillin-sensitive staphylococcus aureus; MRSA, methicillin-resistant staphylococcus aureus; VRE, vancomycin-resistant enterococcus.

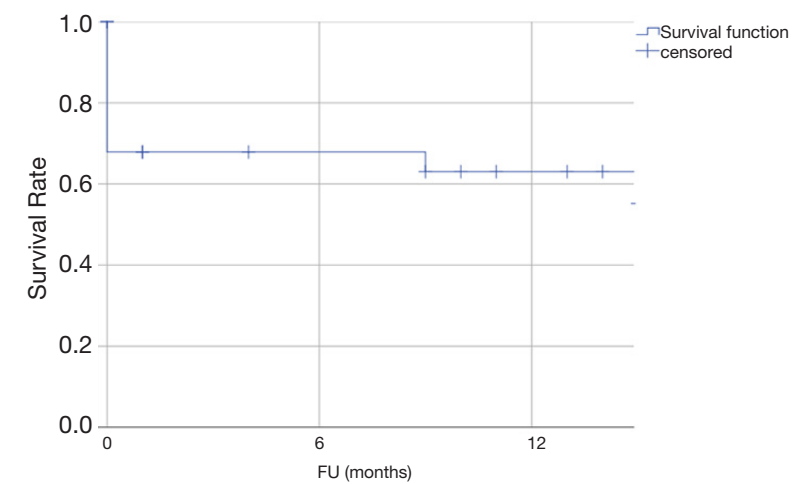

Figure 4 Kaplan-Meier analysis of overall survival. A $10 \%$ standard error was used as cut-off point.

the Omniflow ${ }^{\circledR}$ II graft for the afore-mentioned indications and is the first to describe its use for replacement of the viscerorenal aortic branches. However, in one of those patients an early mesenteric bypass occlusion occurred with subsequent mesenteric ischemia requiring extensive bowel resection. Since no technical problem was found during the revision surgery, the lower resistance to kinking as well as the initially higher thrombogenicity of this graft (6) may have caused this early complication. They should be kept in mind when implanting the Omniflow ${ }^{\circledR}$ II graft and, in addition to precisely following the manufacturers guidelines on appropriate graft rinsing with heparin prior to implantation, a higher anticoagulation regime in the early postoperative period might be considered. However, this has to be weighed individually against the bleeding risk, which represented a relevant complication in this series.

Despite the good technical outcomes in this study, the $32 \%$ early and $39 \%$ overall mortality rates are relevant. Mortality rates of patients with AI can vary significantly depending on multiple factors, i.e., the clinical presentation of the patient or rather the urgency of repair combined with the type and extent of treatment (1). Our results are in accordance with those of most other authors $(4,8,21)$ and reflect the severity of disease in this specific patient cohort in addition to the seriousness of $\mathrm{AI}$ in general. Ongoing sepsis with subsequent multi-organ failure has been reported as a major cause of death in patients after xenogeneic orthotopic aortic reconstructions in AI patients (4). This was also the main cause of death in the majority of the patients in the present study and is also reflected by the higher levels of leukocytes, CRP and PCT in the subgroup of patients who died during the hospital stay. Moreover, comorbidities that are known to increase the 
Table 5 Early complications

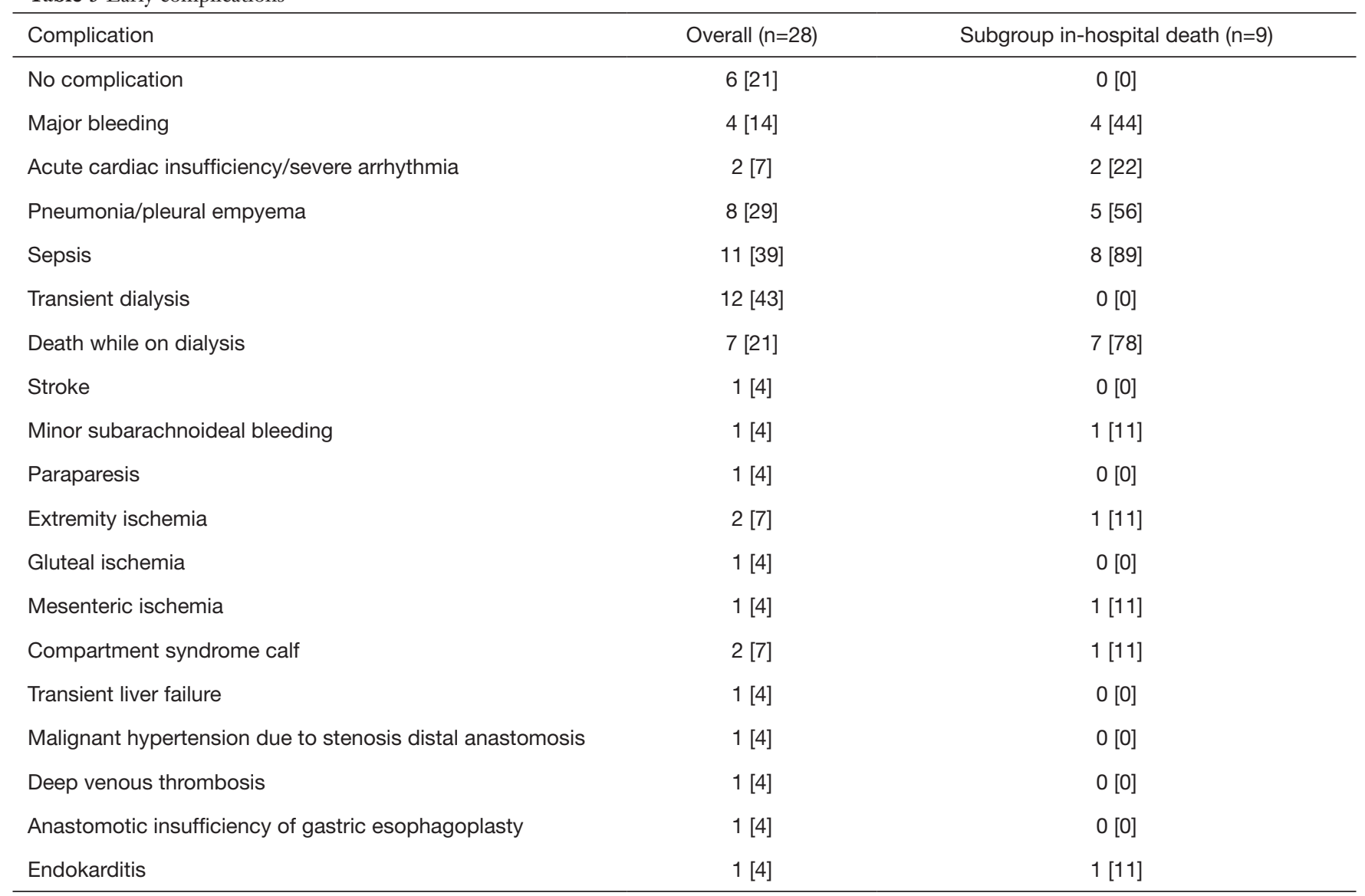

Data are presented as $\mathrm{n}[\%]$.

operative risk such as chronic renal insufficiency, COPD and immunosuppression were more frequent in this subgroup of patients. Bleeding complications, mostly diffuse, represent another important aspect contributing to the early morbidity and mortality in the present cohort. The high proportions of patients presenting with contained rupture (29\%), of patients with prior aortic $(64 \%)$ and prior abdominal non-aortic surgery $(14 \%)$ are a relevant risk factor in this regard.

\section{Limitations}

The retrospective nature of this study as well as the heterogeneity of the procedures including aortic reconstructions at all levels are the main study limitations. However, AIs are rare and the clinical presentation of patients can vary significantly. In addition to presenting our overall experience with these procedures, it was also the aim of this study to point out the applicability of the reported technique for different types of aortic reconstruction thereby increasing the transferability of our findings to similar clinical situations. Finally, in view of the relatively small study population, the lack of $\mathrm{FU}$ data after discharge for two patients is also a limitation of this study.

\section{Conclusions}

Treating patients with AIs is challenging and, as recommended also in the recent guidelines, multidisciplinary expertise is mandatory. Among the available graft materials for aortic reconstruction, bovine pericardium und the biosynthetic Omniflow ${ }^{\circledR}$ II graft represent valuable and versatile alternatives to autologous vein or cryopreserved homografts, especially in case of urgent or emergent procedures. Longterm data are desirable to validate these findings. 


\section{Acknowledgments}

Funding: None.

\section{Footnote}

Reporting Checklist: The authors have completed the STROBE reporting checklist. Available at http://dx.doi. org/10.21037/jtd-20-3481

Data Sharing Statement: Available at http://dx.doi. org/10.21037/jtd-20-3481

Conflicts of Interest: All authors have completed the ICMJE uniform disclosure form (available at http://dx.doi. org/10.21037/jtd-20-3481). DK serves as an unpaid editorial board member of Fournal of Thoracic Disease from Feb 2021 to Jan 2023. The other authors have no conflicts of interest to declare.

Ethical Statement: The authors are accountable for all aspects of the work in ensuring that questions related to the accuracy or integrity of any part of the work are appropriately investigated and resolved. The study was conducted in accordance with the Declaration of Helsinki (as revised in 2013). Ethical board approval was obtained (EK 20-031), individual consent was waived due to the retrospective study design.

Open Access Statement: This is an Open Access article distributed in accordance with the Creative Commons Attribution-NonCommercial-NoDerivs 4.0 International License (CC BY-NC-ND 4.0), which permits the noncommercial replication and distribution of the article with the strict proviso that no changes or edits are made and the original work is properly cited (including links to both the formal publication through the relevant DOI and the license). See: https://creativecommons.org/licenses/by-nc-nd/4.0/.

\section{References}

1. Chakfé N, Diener H, Lejay A, et al. Editor's Choice European Society for Vascular Surgery (ESVS) 2020 Clinical Practice Guidelines on the Management of Vascular Graft and Endograft Infections. Eur J Vasc Endovasc Surg 2020;59:339-84.

2. Heinola I, Sörelius K, Wyss TR, et al. Open Repair of Mycotic Abdominal Aortic Aneurysms With Biological
Grafts: An International Multicenter Study. J Am Heart Assoc 2018;7:e008104.

3. Deipolyi AR, Czaplicki CD, Oklu R. Inflammatory and infectious aortic diseases. Cardiovasc Diagn Ther 2018;8:S61-S70.

4. Hostalrich A, Ozdemir BA, Sfeir J, et al. Systematic review of native and graft-related aortic infection outcome managed with orthotopic xenopericardial grafts. J Vasc Surg 2019;69:614-8.

5. Weiss S, Tobler E, von'Tengg-Kobligk H, et al. Self Made Xeno-pericardial Aortic Tubes to Treat Native and Aortic Graft Infections. Eur J Vasc Endovasc Surg 2017;54:646-52.

6. Töpel I, Uhl C, Ayx I, et al. Xenografts in septic vascular surgery. Gefasschirurgie 2016;21:55-8.

7. Belkorissat RA, Sadoul C, Bouziane Z, et al. Tubular reconstruction with bovine pericardium xenografts to treat native aortic infections. Ann Vasc Surg 2020;64:27-32.

8. Carrel T, Englberger L, Schmidli J. How to treat aortic graft infection? With a special emphasis on xenopericardial aortic tube grafts. Gen Thorac Cardiovasc Surg 2019;67:44-52.

9. Zientara A, Schwegler I, Dzemali O, et al. Xenopericardial self-made tube grafts in infectious vascular reconstructions: Preliminary results of an easy and ready to use surgical approach. Vascular 2016;24:621-7.

10. Neufang A, Duenschede F, Espinola-Klein C, et al. Contemporary results with the biosynthetic glutaraldehyde denatured ovine collagen graft (Omniflow II) in femoropopliteal position. J Vasc Surg 2020;71:1630-43.

11. Töpel I, Stigler T, Ayx I, et al. Biosynthetic Grafts To Replace Infected Prosthetic Vascular Bypasses: A SingleCenter Experience. Surg Infect (Larchmt) 2017;18:202-5.

12. Wiltberger G, Matia I, Schmelzle M, et al. Mid- and long-term results after replacement of infected peripheral vascular prosthetic grafts with biosynthetic collagen prosthesis. J Cardiovasc Surg (Torino) 2014;5 5:693-8.

13. Harmouche M, Loreille F, Le Bars F, et al. Aortic treatment of native infection by reconstruction with the Omniflow II biologic prosthesis. J Vasc Surg Cases Innov Tech 2018;4:296-300.

14. Krasznai AG, Snoeijs M, Siroen MP, et al. Treatment of aortic graft infection by in situ reconstruction with Omniflow II biosynthetic prosthesis. Vascular 2016;24:561-6.

15. Woźniak W, Bajno R, Świder M, et al. The Usefulness of Biosynthetic Vascular Graft Omniflow II and Autologous Veinsfor the Treatment of Massive Infection of Dacron Vascular Graft with Enterococcus faecalis HLAR. Pol J 
Microbiol 2017;65:471-4.

16. Teebken OE, Bisdas T, Assadian O, et al. Recommendations for Reporting Treatment of Aortic Graft Infections. Eur J Vasc Endovasc Surg 2012;43:174-81.

17. Lyons OTA, Baguneid M, Barwick TD, et al. Diagnosis of Aortic Graft Infection: A Case Definition by the Management of Aortic Graft Infection Collaboration (MAGIC). Eur J Vasc Endovasc Surg 2016;52:758-63.

18. Keschenau PR, Kotelis D, Bisschop J, et al. Editor's Choice - Open Thoracic and Thoraco-abdominal Aortic Repair in Patients with Connective Tissue Disease. Eur J Vasc Endovasc Surg 2017;54:588-96.

19. Kotelis D, Gombert A, Jacobs MJ. Treatment of postthoracic endovascular aortic repair aortoesophageal fistula - only radical surgery can be effective: techniques and sequence of treatment. J Thorac Dis 2018;10:3869-73.

20. Schemper M, Smith TL. A note on quantifying follow-up in studies of failure time. Control Clin Trials 1996;17:343-6.

21. Kahlberg A, Melissano G, Mascia D, et al. How to best treat infectious complications of open and endovascular thoracic aortic repairs. Semin Vasc Surg 2017;30:95-102.

22. Smeds MR, Duncan AA, Harlander-Locke MP, et al. Treatment and outcomes of aortic endograft infection. J Vasc Surg 2016;63:332-40.

23. Stenson KM, Grima M, Loftus IM, et al. Recommendations for Management of Infected Aortic Pathology Based on Current Evidence. Semin Vasc Surg 2019;32:68-72.

24. Masabni K, Weaver MR, Kandagatla P, et al.

Cite this article as: Keschenau PR, Gombert A, Barbati ME, Jalaie H, Kalder J, Jacobs MJ, Kotelis D. Xenogeneic materials for the surgical treatment of aortic infections. J Thorac Dis 2021;13(5):3021-3032. doi: 10.21037/jtd-20-3481
Cryopreserved Allograft in the Management of Native and Prosthetic Aortic Infections. Ann Vasc Surg 2019;56:1-10.

25. Almási-Sperling V, Heger D, Meyer A, et al. Treatment of aortic and peripheral prosthetic graft infections with bovine pericardium. J Vasc Surg 2020;71:592-8.

26. Lutz B, Reeps C, Biro G, et al. Bovine pericardium as new technical option for in situ reconstruction of aortic graft infection. Ann Vasc Surg 2017;41:118-26.

27. Woźniak W, Kozińska A, Ciostek P, et al. Susceptibility of Vascular Implants to Colonization in vitro by Staphylococcus aureus, Staphylococcus epidermidis, Enterococcus faecalis and Pseudomonas aeruginosa. Pol J Microbiol 2017;66:125-9.

28. Terlecki P, Zubilewicz T, Wojtak A, et al. Replacement of infected aortoiliac vascular grafts with bifurcated BioIntegral Surgical No-React@ bovine pericardial xenografts. Xenotransplantation 2019;26:e12496.

29. Burghuber CK, Konzett S, Eilenberg W, et al. Novel Prefabricated Bovine Pericardial Grafts as Alternate Conduit for Septic Aorto-Iliac Reconstruction. J Vasc Surg 2020. [Epub ahead of print]. doi: 10.1016/ j.jvs.2020.11.028.

30. Koch G, Gutschi S, Pascher O, et al. Omniflow Vascular Prostheses implanted over an eight-year period. Aust N Z J Surg 1997;67:637-9.

31. Betz T, Neuwerth D, Steinbauer M, et al. Biosynthetic Vascular Graft: A Valuable Alternative to Traditional Replacement Materials for Treatment of Prosthetic Aortic Graft Infection? Scand J Surg 2019;108:291-6. 


\section{Supplementary}

\begin{tabular}{|c|c|c|c|c|c|c|c|c|c|c|c|c|}
\hline Patient number &  & Gender & Diagnosis & 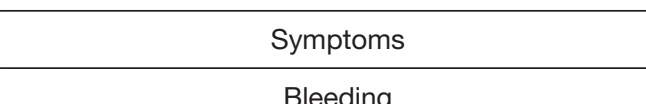 & 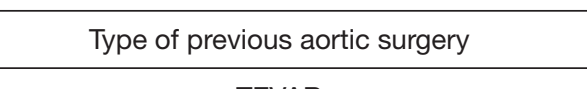 & $\begin{array}{l}\text { Previous non-aoticic open surgery } \\
\end{array}$ & Pathogen & Type of tepair & Material used for reconstruction & Early complications & Complications suring follow-up & Death yes noo) \\
\hline 1 & 66 & M & $\begin{array}{l}\text { AEF } \\
\text { Mvotic iffrerana PAu }\end{array}$ & $\begin{array}{l}\text { Blleding } \\
\text { Continat ruture }\end{array}$ & TEVAR & Esophagectomy & Enterocococus faecium & $\underset{\text { TAAa }}{\text { TAfreala }}$ & Eovine & & & No \\
\hline${ }_{3}^{2}$ & ${ }_{62}^{72}$ & ${ }_{M}^{M}$ & 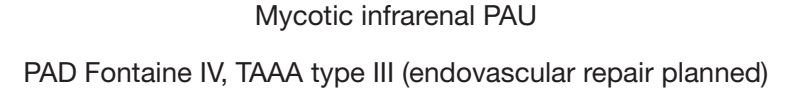 & 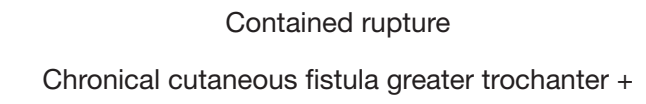 & $\begin{array}{l}\text { None } \\
\text { inftranena biturated grat (artobitiac) }\end{array}$ & & Enterecocous facalis, Cornebacterium & Inffarenal & $\begin{array}{l}\text { Bovine } \\
\text { Bovine+ Omniffow" }\end{array}$ & Gilteal ischemia & & No \\
\hline${ }^{4}$ & 68 & m & 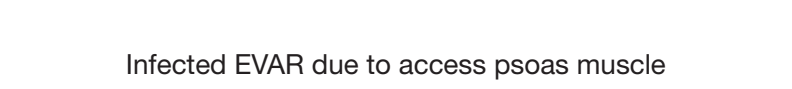 & $\begin{array}{l}\text { Ischium } \\
\text { Recurrent fever }\end{array}$ & EVAR & & 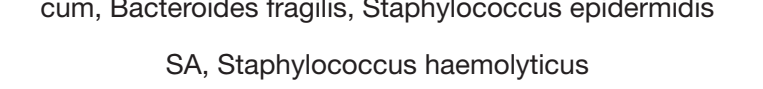 & Juxtarenal & Bovine OMmifliow" II & 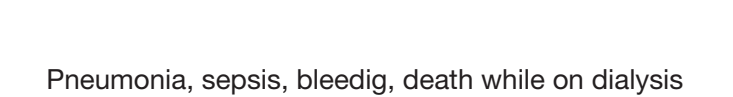 & & Yes \\
\hline 5 & 84 & м & Mycotic infarenenal AAA + lilic artery aneurssm & Contained rupture, sepsis & & & SA & Intraenal & Bovine & 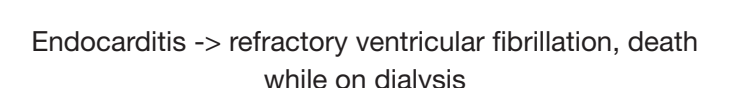 & & yes \\
\hline 6 & 78 & м & TAAAtpoe IV & Contained rupture, sepsis & EVAR & & Escherichia coli & TAAAtype IV & Bovine + Omnifiow"ll & 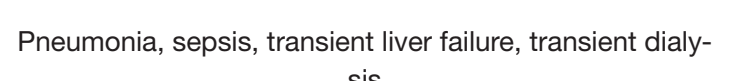 & & № \\
\hline 7 & 76 & $\mathrm{~F}$ & Large periprostheticif fluid collections & None & 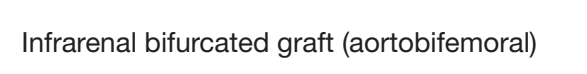 & & Staphylococous Iugdunensis & inftarenal & Omnitiow" II & & & No \\
\hline 8 & 52 & м & Inflammatory TAAA type IV & None & & $\begin{array}{l}\text { Partial resection of ilium for perforation due to foreign } \\
\text { bocyl ingstion }\end{array}$ & $\begin{array}{l}\text { Initially: none; a Ater revision for paralytici ileus: Escherichia } \\
\text { coli ivVEE }\end{array}$ & TAAAtype V & Bovine+ Omnitiow" II & & & Yes \\
\hline 9 & 72 & м & Mycotic infrarenal AAA & Abdominal pain & & & Listeria monocytogenes & Inffarenal & Omnitiow" II & & & № \\
\hline 10 & 70 & м & Type la endoleak, Aortitis & Unspectific symptoms/tatiaue & BEAAR & & Staphylococous epidermidis & TAA & Bovine & Acute cardiac insurficieinny & & Yes \\
\hline 11 & 42 & $\mathrm{~F}$ & AEF, mediastinitis & Atory intections, cough, tit & 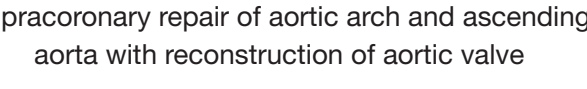 & & Lactobacilus thammosus & 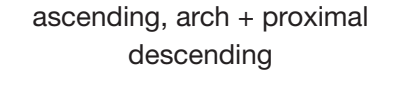 & Bovine & 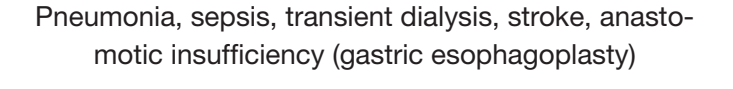 & & oo \\
\hline 12 & 67 & M & Myocotic TAAA type V & 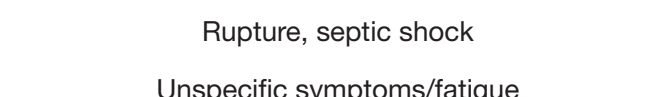 & TEVAR+ Chimmey coliac trune & & 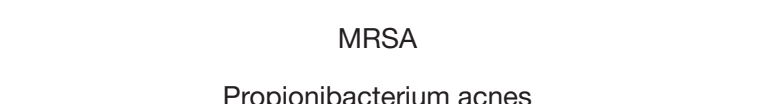 & TAAA type V & Bouine & Bleding, sepsis, death while on dialysis & & Yes \\
\hline${ }_{14}^{13}$ & ${ }_{69}^{73}$ & ${ }_{M}^{M}$ & 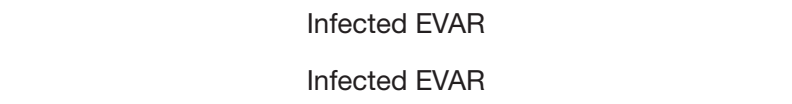 & 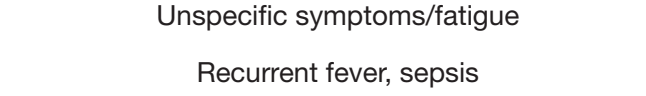 & $\begin{array}{l}\text { ENAR } \\
\text { EVAR }\end{array}$ & & 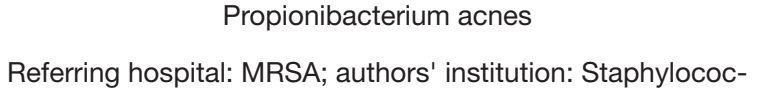 & $\begin{array}{l}\text { JuXtarenal } \\
\text { INFAAENAL }\end{array}$ & 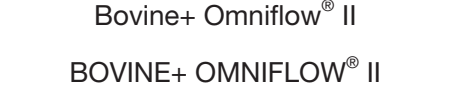 & Pneumonia, sepsis, transient dialysis & Repari of fincisional herria & Yes \\
\hline 15 & 66 & м & ADF & strointestina bleding requ & 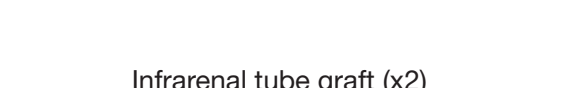 & & 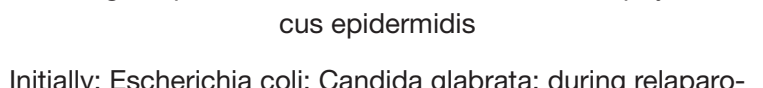 & 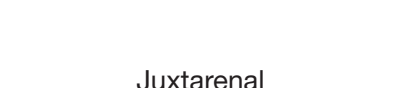 & (2) & & & \\
\hline & & & nes & transtusion & 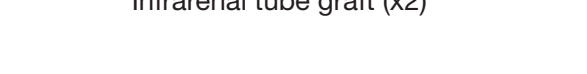 & & $\begin{array}{l}\text { tomy aterer } 3 \text { weeks: VRE } \\
\text { the }\end{array}$ & Juxaterat & Dounte & 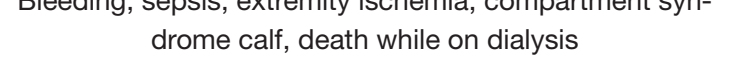 & & Yes \\
\hline 16 & 53 & м & Infected TEVAR & Sepsis & TEVAR + Chimmey left subcavaia atery & & SA & TAA + lett subclavian bypass & Bovine + Omnitiow ${ }^{\circ}$ I & 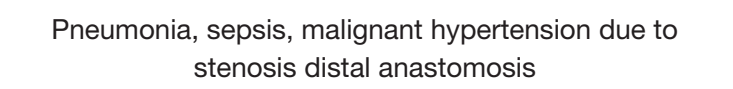 & & № \\
\hline 17 & 28 & $\mathrm{~F}$ & High-grade carcinoma of felopian tube & Hemorragicis shock & & 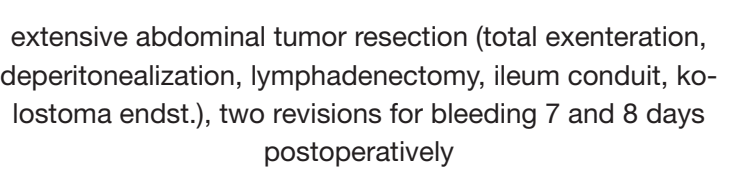 & intitally: Candida albicans, during revision surgery: VRE & infraenal & Omnitiowa II &  & & res \\
\hline 18 & 62 & M & Ureteral fistula & Weight toss, nausea, unspectific abdominal pain & 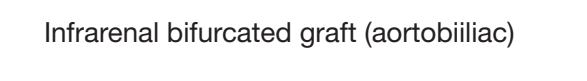 & & None & Inffarenal & Ominitow"ll & &  & № \\
\hline 19 & 45 & m & Inffammatory inffraenal PAU & Contained rupture & & & None & Juxtarenal & omnitiow"II & & & № \\
\hline${ }^{20}$ & 77 & M & myotic aneurssmm brachiocephalic trunc & sepsis, tracheal compression & & & SA, Enterocococuus taecium & $\begin{array}{l}\text { scending +right carorid and } \\
\text { right subchavianan yypass }\end{array}$ & bovine+ Omnitiow"ll & pneumonia, sepsis & & Yes \\
\hline & 72 & м & ADF & Sepsis & Infrarenal bifurcated gratat (aortobilinac) & & Streptitcococus constellatus; ; Strepticococus oralis & Intratenal & bovine+ Omniflow"III & & & No \\
\hline${ }_{23}^{22}$ & 58 & ${ }_{M}^{M}$ & 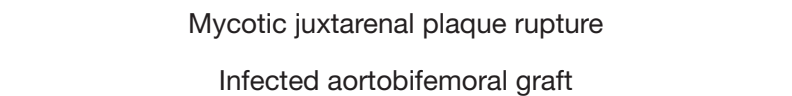 & $\begin{array}{l}\text { Ruputur } \\
\text { Sosis }\end{array}$ & 8) intar & &  & Juxtarenal & 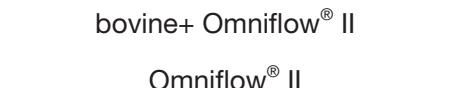 & 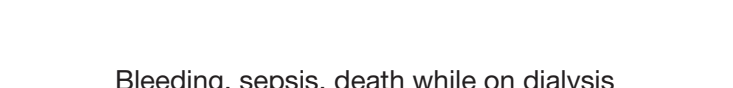 & & Yes \\
\hline 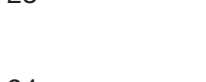 & & & & Sepsis & 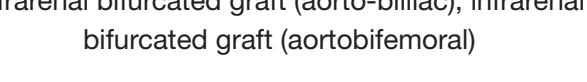 & & & Infraenal & Omnifiow'tl & 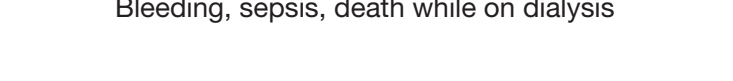 & & Yes \\
\hline${ }^{24}$ & ${ }_{71}^{76}$ & $\mathrm{M}_{\mathrm{F}}$ & $\begin{array}{l}\text { Infiected EVAR, Type I EL } \\
\text { TAAA }\end{array}$ & Contanind noture & EVAR & & $\begin{array}{l}\text { Propionibacterium acness; Staph. Haemolyticus } \\
\text { strent }\end{array}$ & 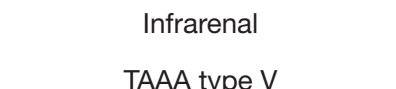 & 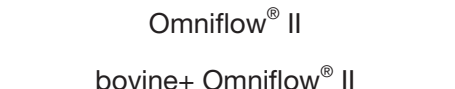 & 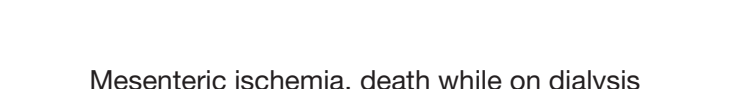 & & No \\
\hline 26 & 71 & $\mathrm{~F}$ & 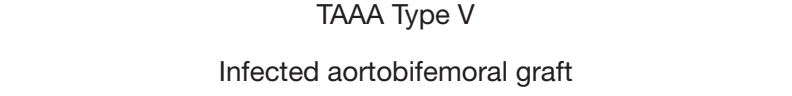 & $\begin{array}{l}\text { None } \\
\text { None }\end{array}$ & Inffrerenal aortobifemoral & & $\begin{array}{l}\text { Strept. Pneunoniae } \\
\text { None }\end{array}$ & 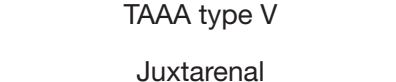 & 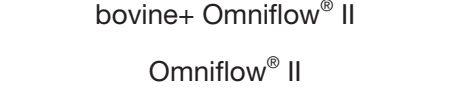 & Mesentercic schemala, death While on dialysis & & Yes \\
\hline 27 & 61 & м & Infraena A A AA +juxxarenal PAU & Contained rupture & & & SA; C. alb, E. coll, Enterocococus avium, Morg, morganii, & Juxtarenal & bovinet Omnitilow" II & 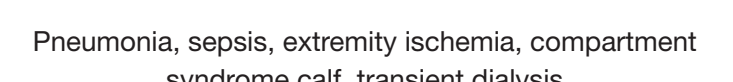 & & No \\
\hline 28 & 59 & м & AEF & Bleeding, sepsis & TEAAR & & MRSA, VRE & TAA & Bovine & Pnoumonia, sepsis, paraperestis, transisient tialaysis & & No \\
\hline
\end{tabular}

